\title{
Processable and Luminescent Supramolecular Hydrogels from Complex Coacervation of Polycations with Lanthanide Coordination Polyanions
}

Jiahua Wang, ${ }^{\dagger}$ Shengtong Sun, ${ }^{*}, \star$ Bohang Wu,${ }^{\dagger}$ Lei Hou, ${ }^{\ddagger}$ Peng Ding,${ }^{\dagger}$ Xuhong Guo, ${ }^{\dagger}$ Martien A. Cohen Stuart, ${ }^{\dagger}$ and Junyou Wang ${ }^{*}, \dagger$

*Corresponding authors: junyouwang@ecust.edu.cn; shengtongsun@dhu.edu.cn

\section{This material includes:}

Figure S1. ${ }^{1} \mathrm{H}-\mathrm{NMR}$ spectra of MPTC monomer.

Figure S2. ${ }^{1} \mathrm{H}-\mathrm{NMR}$ spectra of PMPTC.

Figure S3. ${ }^{1} \mathrm{H}-\mathrm{NMR}$ spectra of $\mathrm{L}_{2} \mathrm{EO}_{4}$.

Figure S4. ${ }^{1} \mathrm{H}-\mathrm{NMR}$ spectra of $\mathrm{La}_{-} \mathrm{L}_{2} \mathrm{EO}_{4}$ coordination polymer.

Figure S5. Quantitative analysis of the composition of the hydrogel with ${ }^{1} \mathrm{H}-\mathrm{NMR}$ and ICPAES.

Figure S6. Emission and pictures of the hydrogel.

Figure S7. Influence of lanthanide ions on the storage and loss moduli of $\mathrm{Ln}-\mathrm{L}_{2} \mathrm{EO}_{4}-\mathrm{PMPTC}$ hydrogel versus frequency.

Figure S8. UV-vis-NIR spectrum of the hydrogel sheet.

Figure S9. Rheological strain oscillatory rheology of the hydrogel.

Figure S10. A comparison of storage modulus $\left(\mathrm{G}^{\prime}\right)$ with other supramolecular gels.

Figure S11. Photo images of the $\mathrm{Zn}-\mathrm{L}_{2} \mathrm{EO}_{4}-\mathrm{PMPTC}$ coacervate complexes.

Figure S12. Control experiment on the acryloyl-based $\mathrm{Ln}_{-} \mathrm{L}_{2} \mathrm{EO}_{4}-\mathrm{PMATAC}$ complexes.

Figure S13. Dynamic mechanical behavior of the supramolecular networks at $0.2 \mathrm{M} \mathrm{NaCl}$.

Figure S14. Dynamic mechanical behavior of the supramolecular networks at $0.3 \mathrm{M} \mathrm{NaCl}$.

Figure S15. Quantitative analysis of the composition of the hydrogel with ${ }^{1} \mathrm{H}-\mathrm{NMR}$ and ICPAES at different temperatures.

Figure S16. Frequency dependency of complex viscosity.

Figure S17. The recyclability of the hydrogel.

Figure S18. Compression stress-strain curves of the hydrogel.

Figure S19. The draw-spinning method to generate luminescent microfibers.

Figure S20. Hydrogel fiber are retained at $100{ }^{\circ} \mathrm{C}$, and its performance as humidity sensor.

Table S1. The apparent activation energy of $\mathrm{Tb}-\mathrm{L}_{2} \mathrm{EO}_{4}-\mathrm{PMPTC}$ hydrogels with various salt concentrations. 


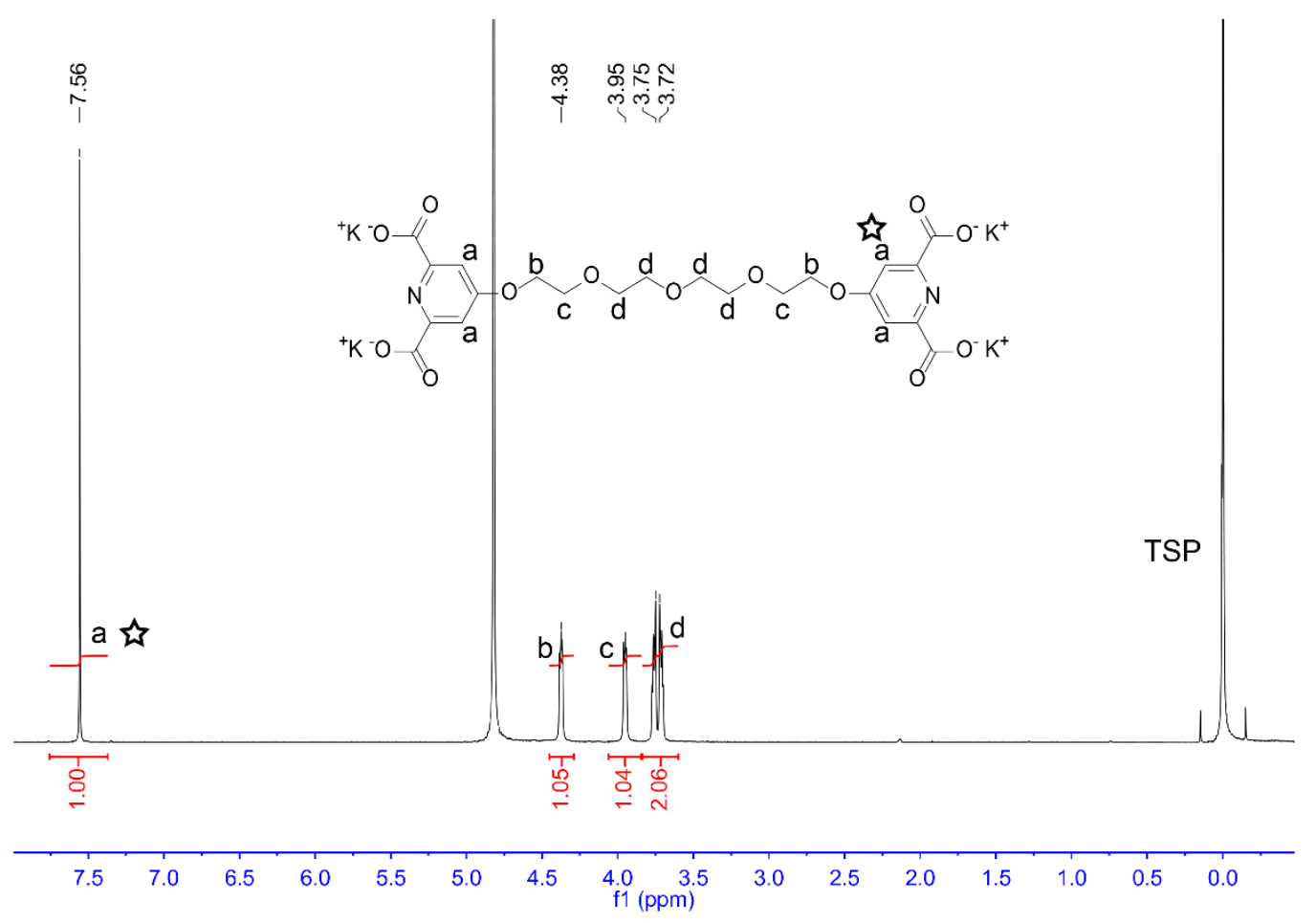

Figure S1. ${ }^{1} \mathrm{H}-\mathrm{NMR}$ spectrum of $\mathrm{L}_{2} \mathrm{EO}_{4}\left(\mathrm{D}_{2} \mathrm{O}\right)$.

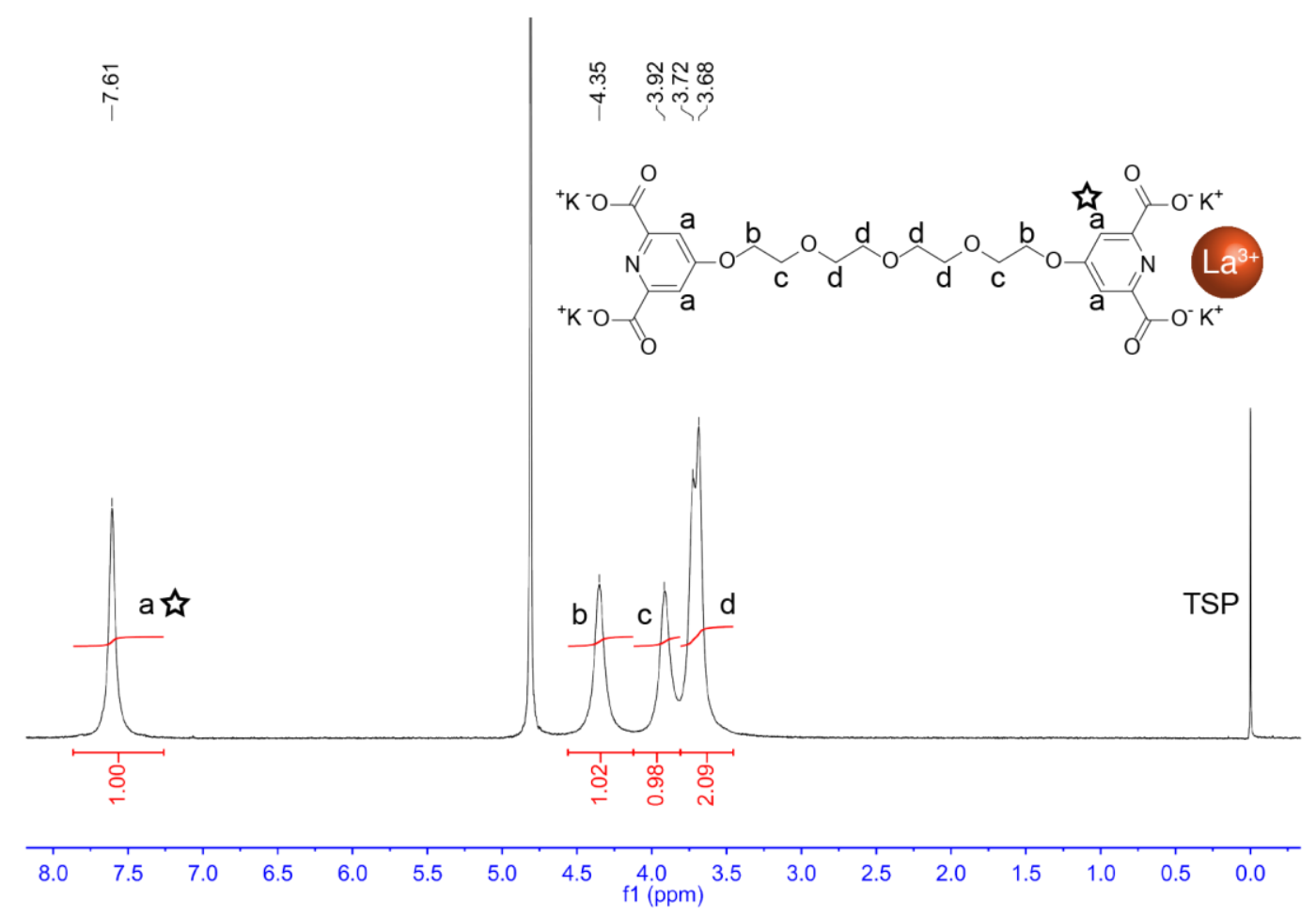

Figure S2. ${ }^{1} \mathrm{H}-\mathrm{NMR}$ spectrum of $\mathrm{La}_{-} \mathrm{L}_{2} \mathrm{EO}_{4}$ coordination polymer $\left(\mathrm{D}_{2} \mathrm{O}\right)$. 


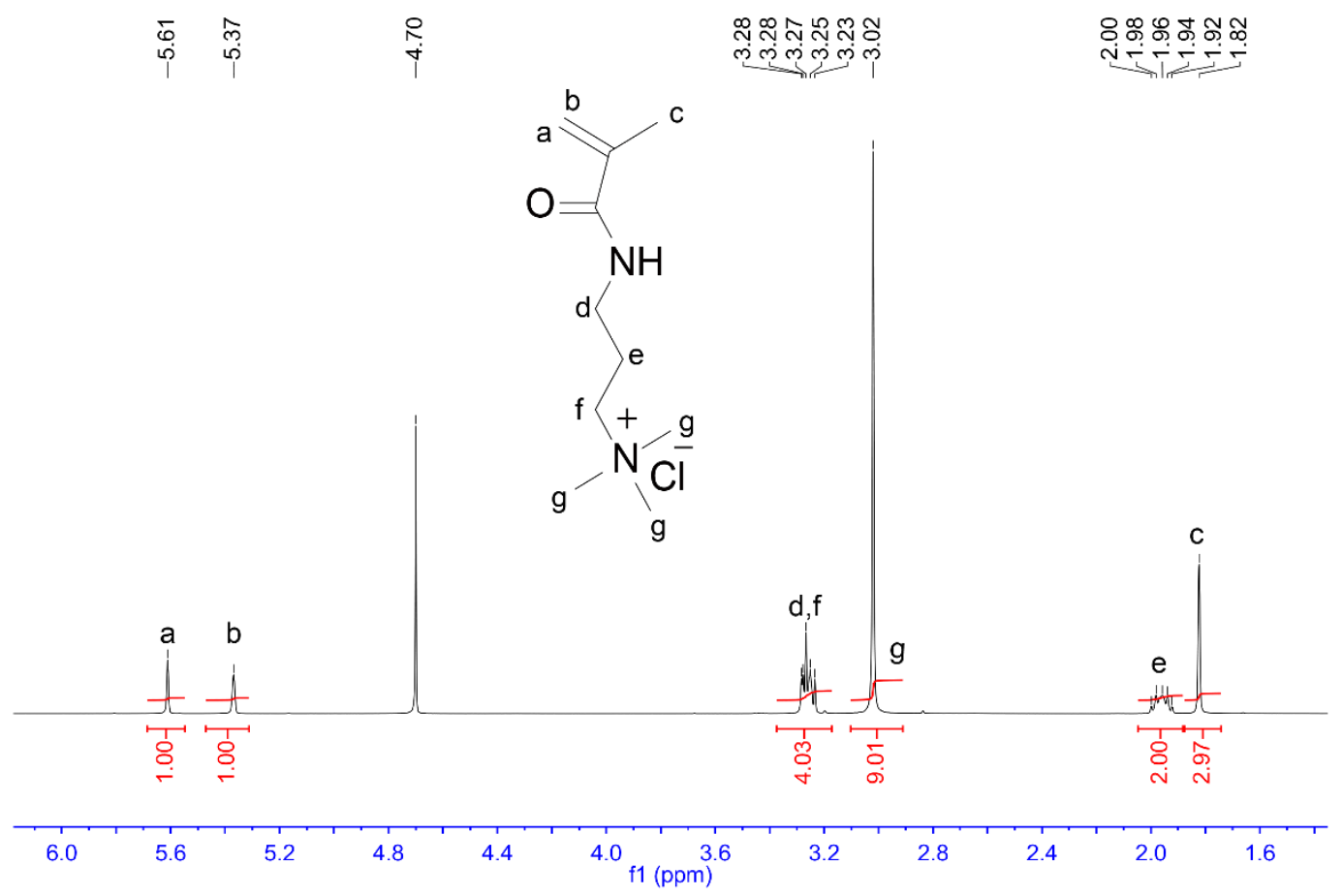

Figure S3. ${ }^{1} \mathrm{H}-\mathrm{NMR}$ spectrum of MPTC monomer $\left(\mathrm{D}_{2} \mathrm{O}\right)$.

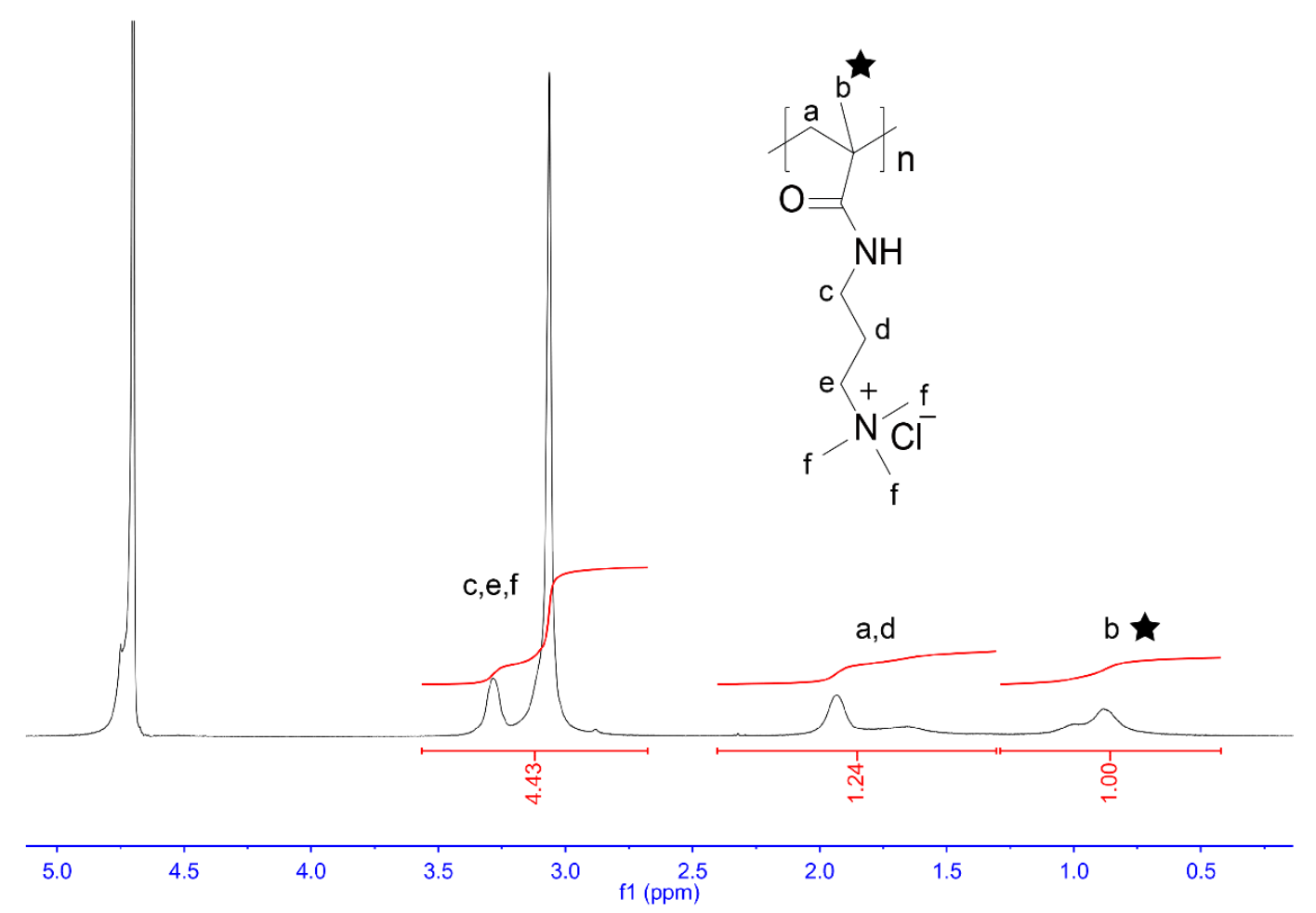

Figure S4. ${ }^{1} \mathrm{H}-\mathrm{NMR}$ spectrum of PMPTC $\left(\mathrm{D}_{2} \mathrm{O}\right)$. 

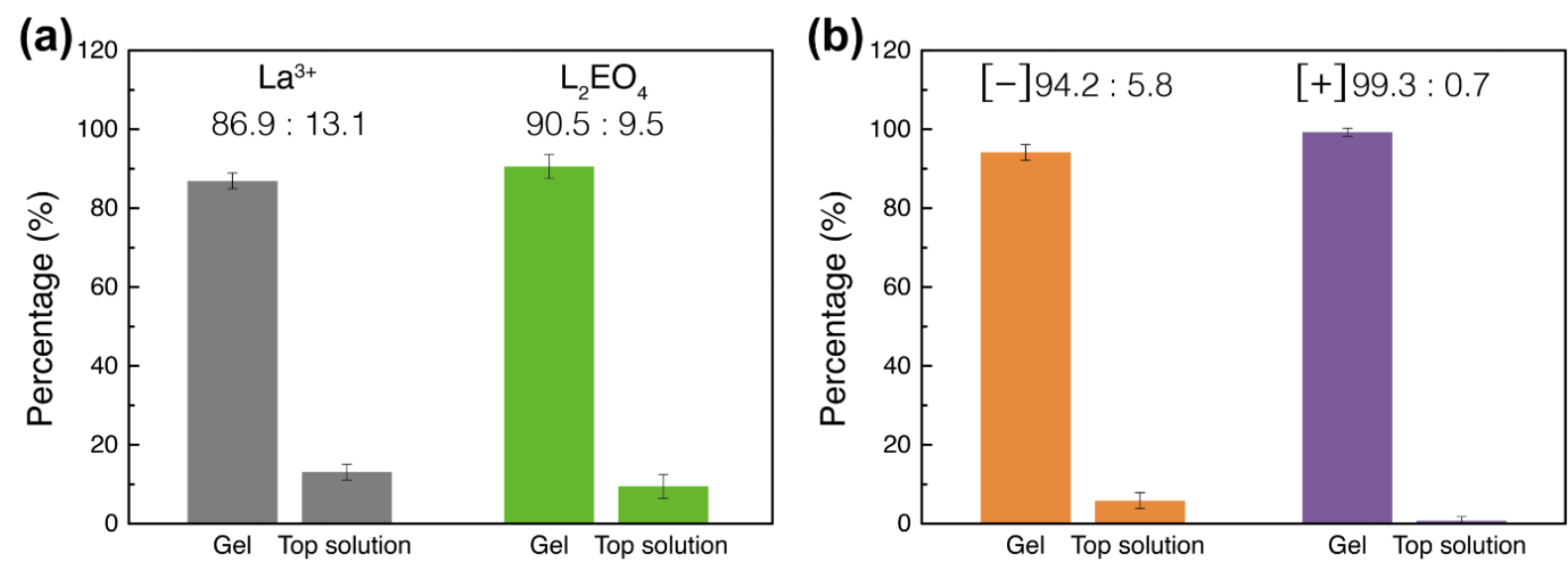

Figure S5. (a) Metal and ligand percentage in the top solution and hydrogel. (b) Charge percentage of $\mathrm{La}-\mathrm{L}_{2} \mathrm{EO}_{4}$ coordination polymer (negatively charged) and PMPTC (positively charged) in the top solution and hydrogel, and the overall charge mixing ratio $f$ - is 0.5 .

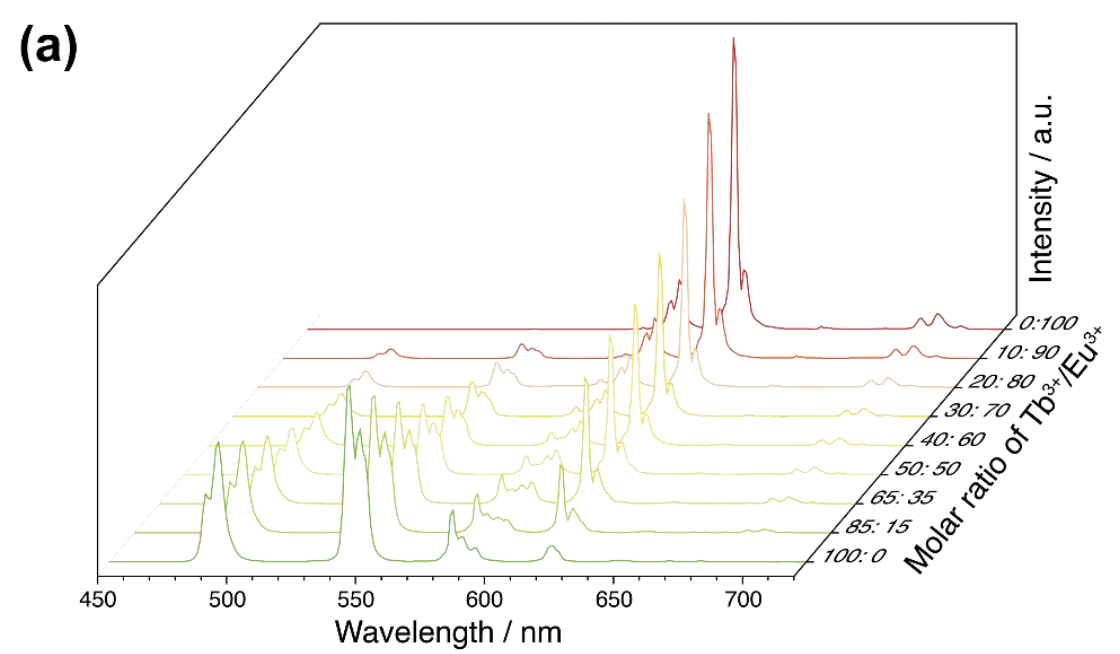

(b)

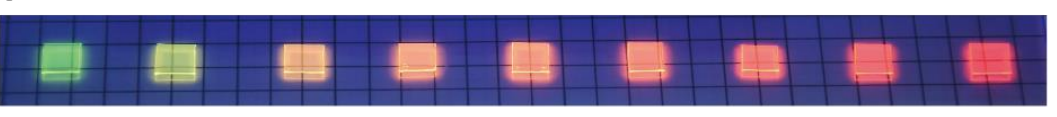

Figure S6. (a) Luminescent emission spectra of the coacervate hydrogels with various molar ratios of $\mathrm{Eu}^{3+}$ and $\mathrm{Tb}^{3+}\left(\lambda_{\mathrm{ex}}=285 \mathrm{~nm}\right)$ corresponding to Fig. 1E. The emission spectrum of the Tb-L $\mathrm{L}_{2} \mathrm{EO}_{4}-\mathrm{PMPTC}$ hydrogel consists of four sharp emission bands at 495, 545, 588 and 621 $\mathrm{nm}$. The primary band at $545 \mathrm{~nm}$ is responsible for the green emission. Emission spectral studies revealed that the intensity of the green band at $545 \mathrm{~nm}$ increased gradually at the expense of the intensity of the red band at $616 \mathrm{~nm}$ as a function of $\mathrm{Tb}^{3+} / \mathrm{Eu}^{3+}$ molar ratio. (b) The coacervate hydrogel pictures under $254 \mathrm{~nm}$ UV lamp illumination (daylight) corresponding to Fig. 1E (from left to right: $\mathrm{Tb}^{3+} / \mathrm{Eu}^{3+}=100: 0,85: 15,65: 35,50: 50,40: 60,30: 70,20: 80,10: 90,0: 100$ ). 


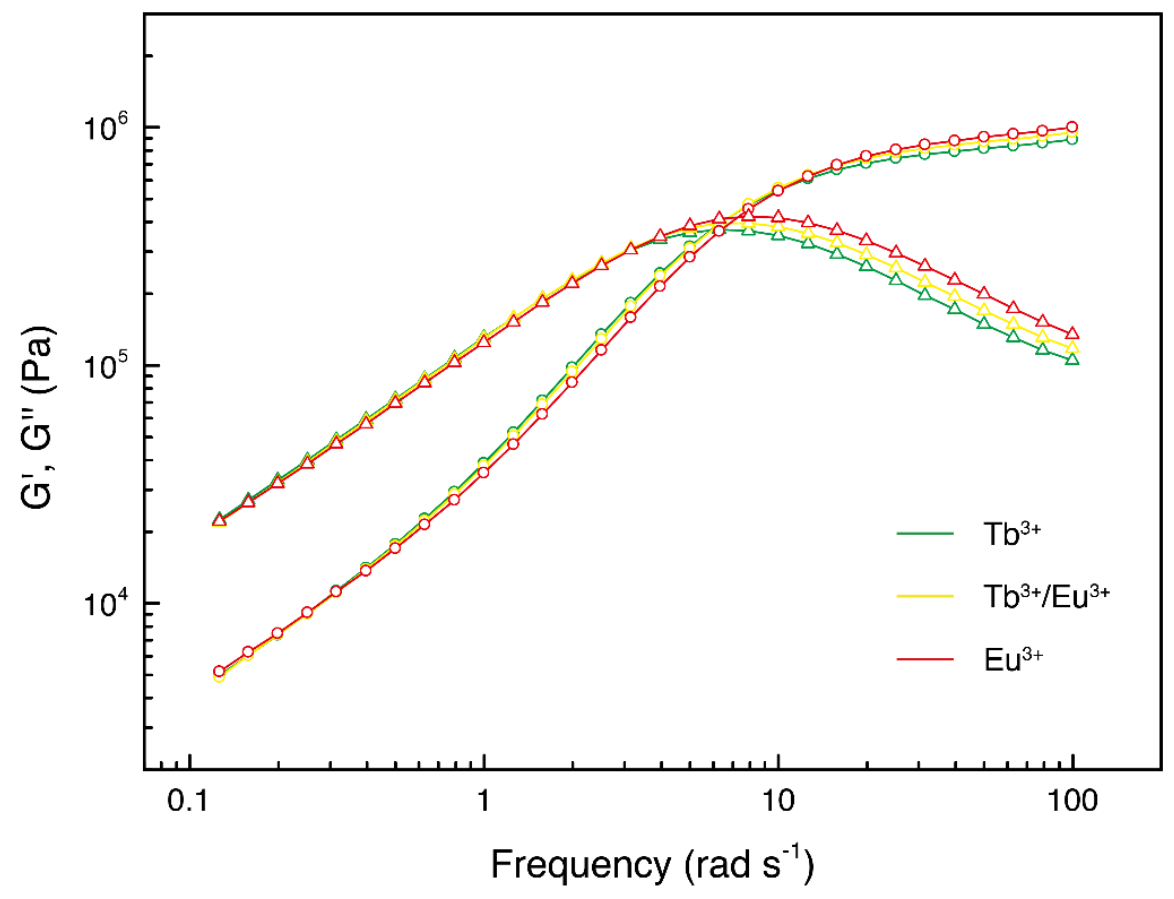

Figure S7. Influence of lanthanide ions on the storage ( $\mathrm{G}^{\prime}$, circles) and loss moduli ( $\mathrm{G}^{\prime \prime}$, triangles) of $\mathrm{Ln}_{-} \mathrm{L}_{2} \mathrm{EO}_{4}-\mathrm{PMPTC}$ hydrogel versus frequency: Tb- $\mathrm{L}_{2} \mathrm{EO}_{4}-\mathrm{PMPTC}$ hydrogel (green), $\mathrm{Tb} / \mathrm{Eu}-\mathrm{L}_{2} \mathrm{EO}_{4}-\mathrm{PMPTC}$ co-doped hydrogel (yellow, $\mathrm{Tb}^{3+} / \mathrm{Eu}^{3+}=1: 1$ ) and $\mathrm{Eu}-\mathrm{L}_{2} \mathrm{EO}_{4-}$ PMPTC hydrogel (red) at $20^{\circ} \mathrm{C}$.

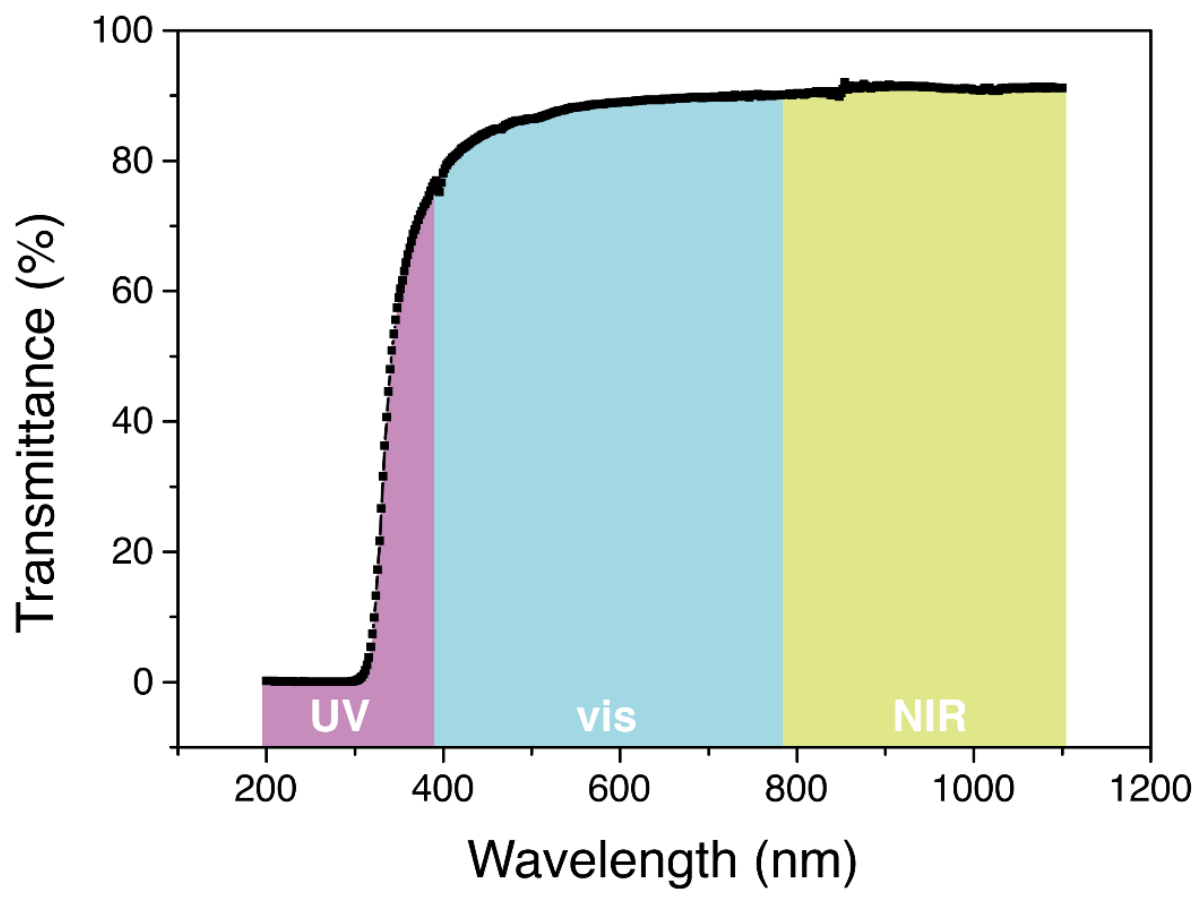

Figure S8. UV-vis-NIR spectrum of $\mathrm{Tb}_{2} \mathrm{~L}_{2} \mathrm{EO}_{4}-\mathrm{PMPTC}$ hydrogel sheet with an average thickness of $0.3 \mathrm{~mm}$. 


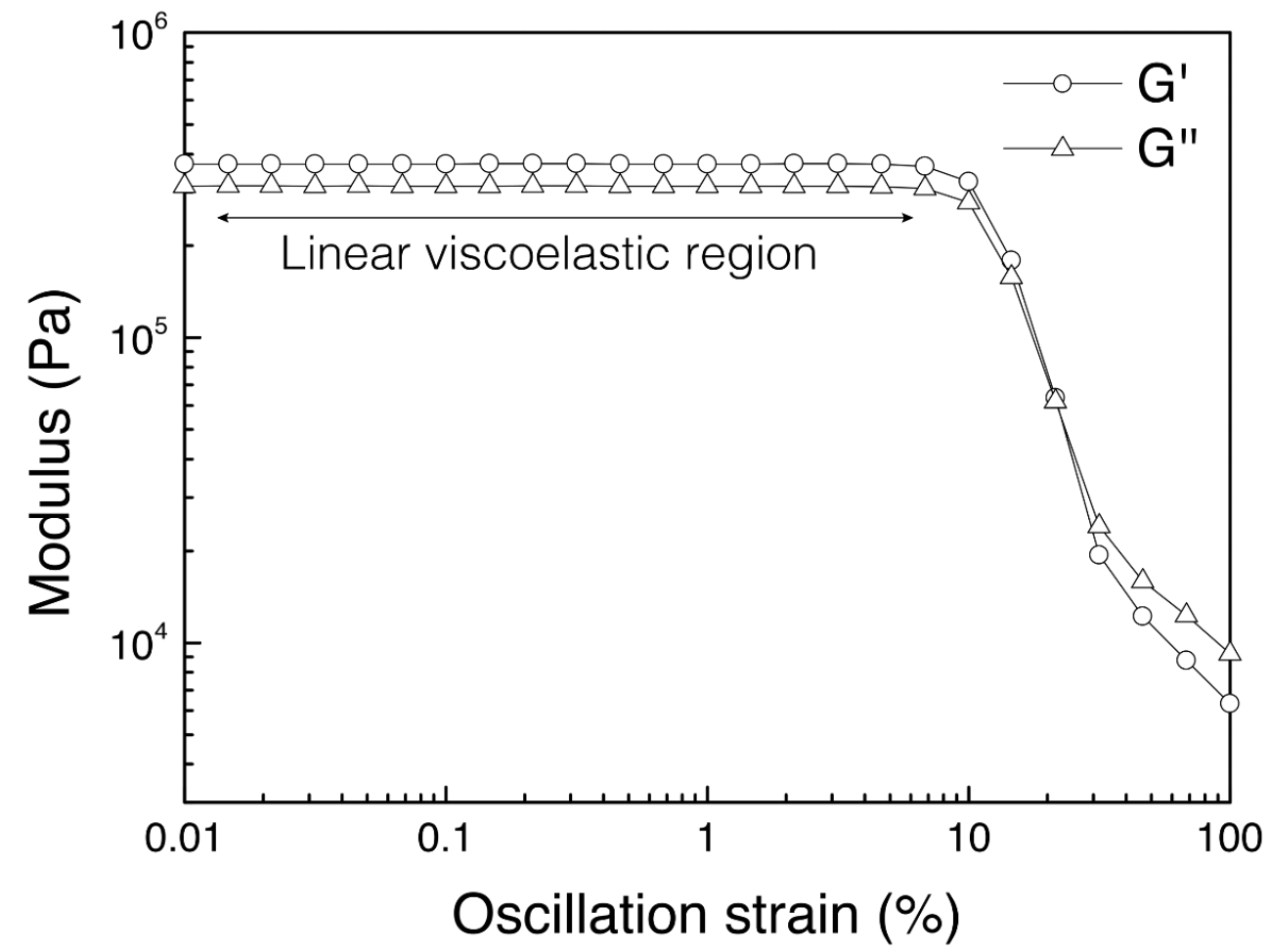

Figure S9. Rheological strain oscillatory rheology of Tb- $\mathrm{L}_{2} \mathrm{EO}_{4}-\mathrm{PMPTC}$ hydrogel from 0.01 to $100 \%$ at $20^{\circ} \mathrm{C}(\omega=10 \mathrm{rad} / \mathrm{s})$.

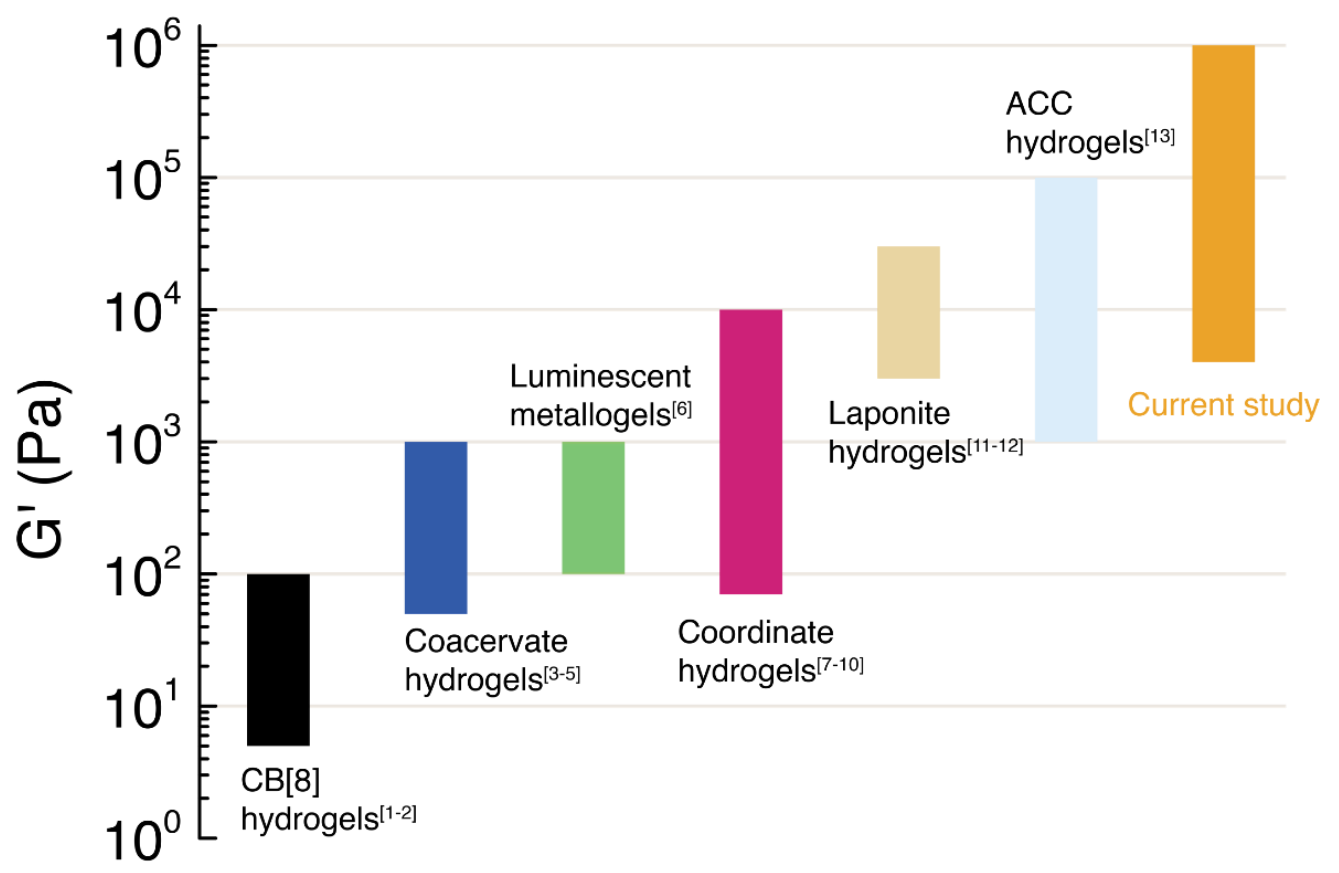

Figure S10. A comparison of the storage modulus $\left(\mathrm{G}^{\prime}\right)$ of $\mathrm{Tb}-\mathrm{L}_{2} \mathrm{EO}_{4}-\mathrm{PMPTC}$ hydrogel in the current study with other typical supramolecular gels in the frequency range of $0.1 \sim 100 \mathrm{rad} / \mathrm{s}^{1-}$ 13. 

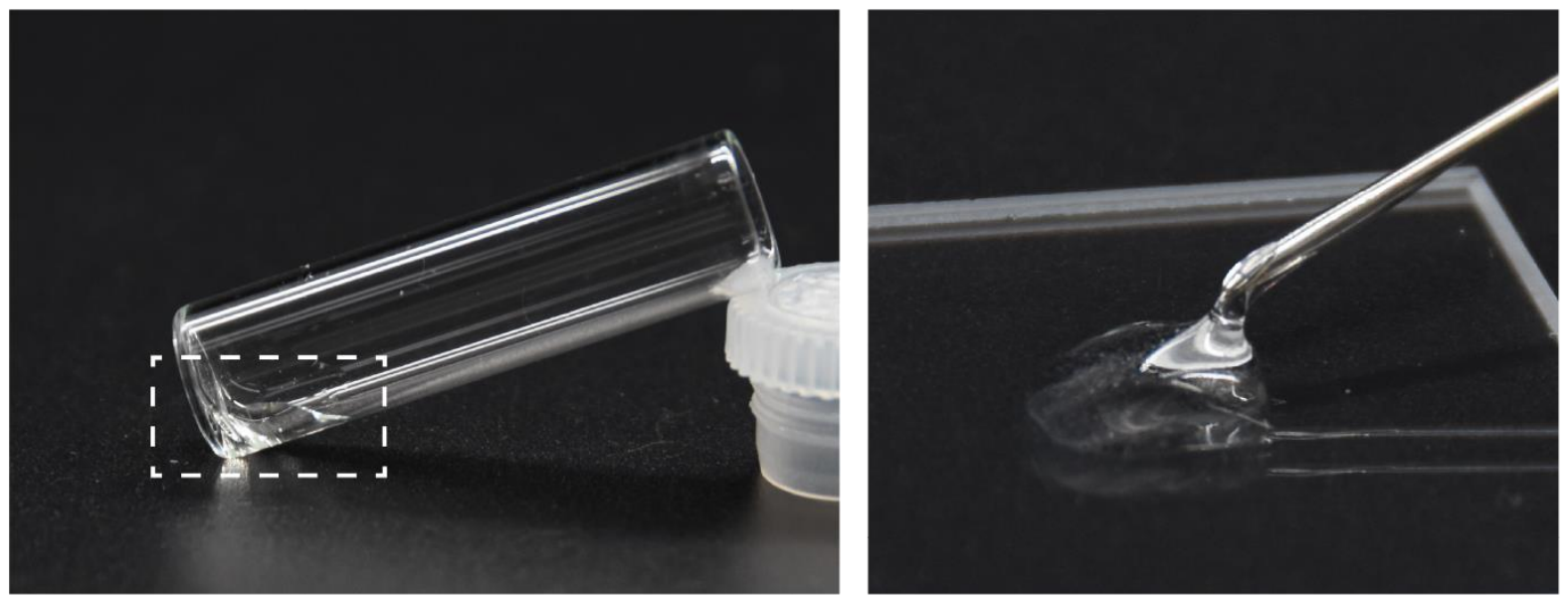

Figure S11. Photo images of the $\mathrm{Zn}-\mathrm{L}_{2} \mathrm{EO}_{4}-\mathrm{PMPTC}$ coacervate complexes. $\mathrm{M} / \mathrm{L}$ is fixed at $1 / 1$, and charge mixing ratio $f$ - is 0.5 .
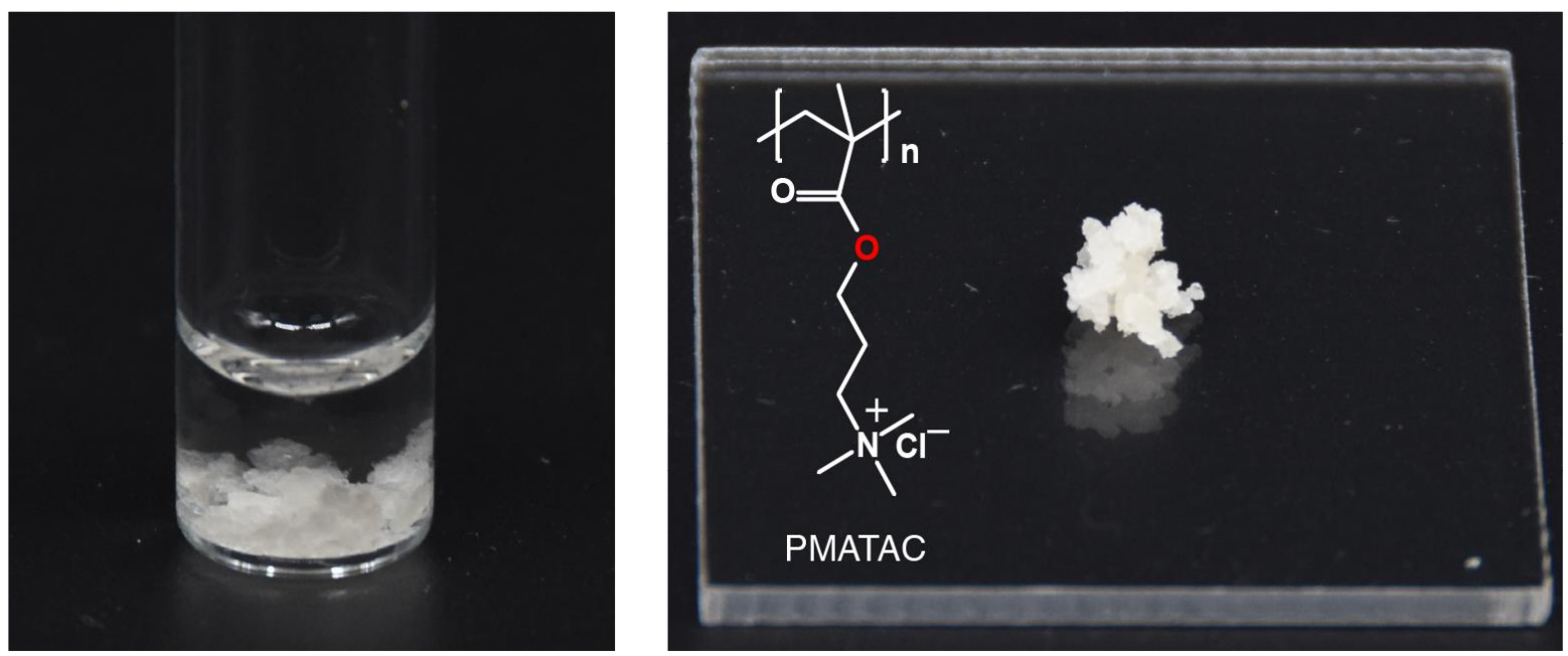

Figure S12. Control experiment on the acryloyl-based poly(methacrylatoethyl trimethyl ammonium chloride) (PMATAC) $-\mathrm{L}_{2} \mathrm{EO}_{4}$ - $\mathrm{Ln}$ hydrogel showing less transparency and no selfhealing properties. 

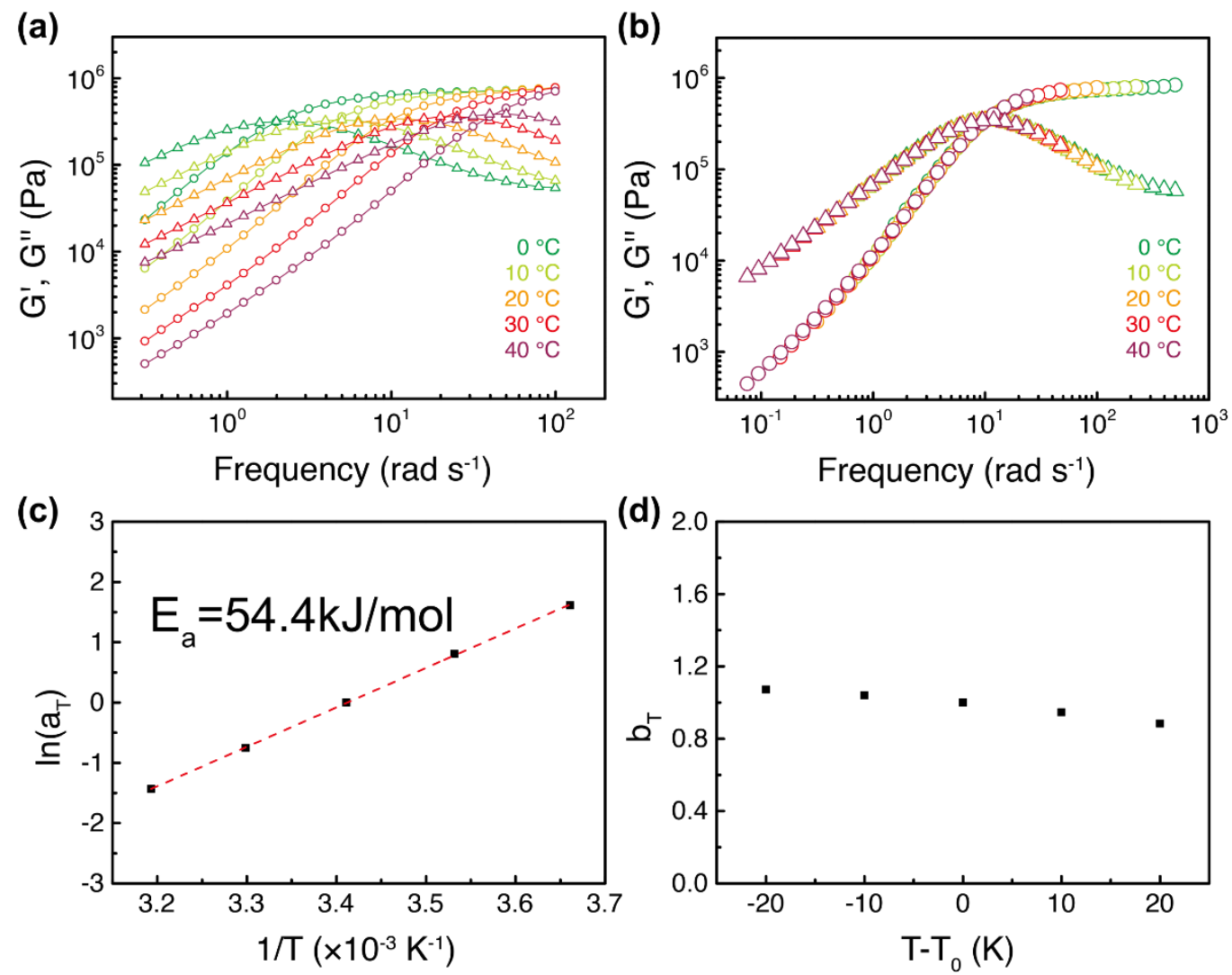

Figure S13. Dynamic mechanical behavior of Tb-L2 $\mathrm{EO}_{4}-\mathrm{PMPTC}$ hydrogels with $0.2 \mathrm{M}$

NaCl. (a) Temperature effect on the rheological behavior. (b) Classical time-temperature superposition shifts at a reference temperature of $20^{\circ} \mathrm{C}$. (c) Time-temperature horizontal shift factor $\left(\mathrm{a}_{\mathrm{T}}\right)$ derived from Arrhenius equation. The apparent activation energy of $54.4 \mathrm{~kJ} \mathrm{~mol}^{-1}$ were calculated from the slope of the curve. (d) Vertical shift factor $\left(\mathrm{b}_{\mathrm{T}}\right)$ as a function of temperature. 

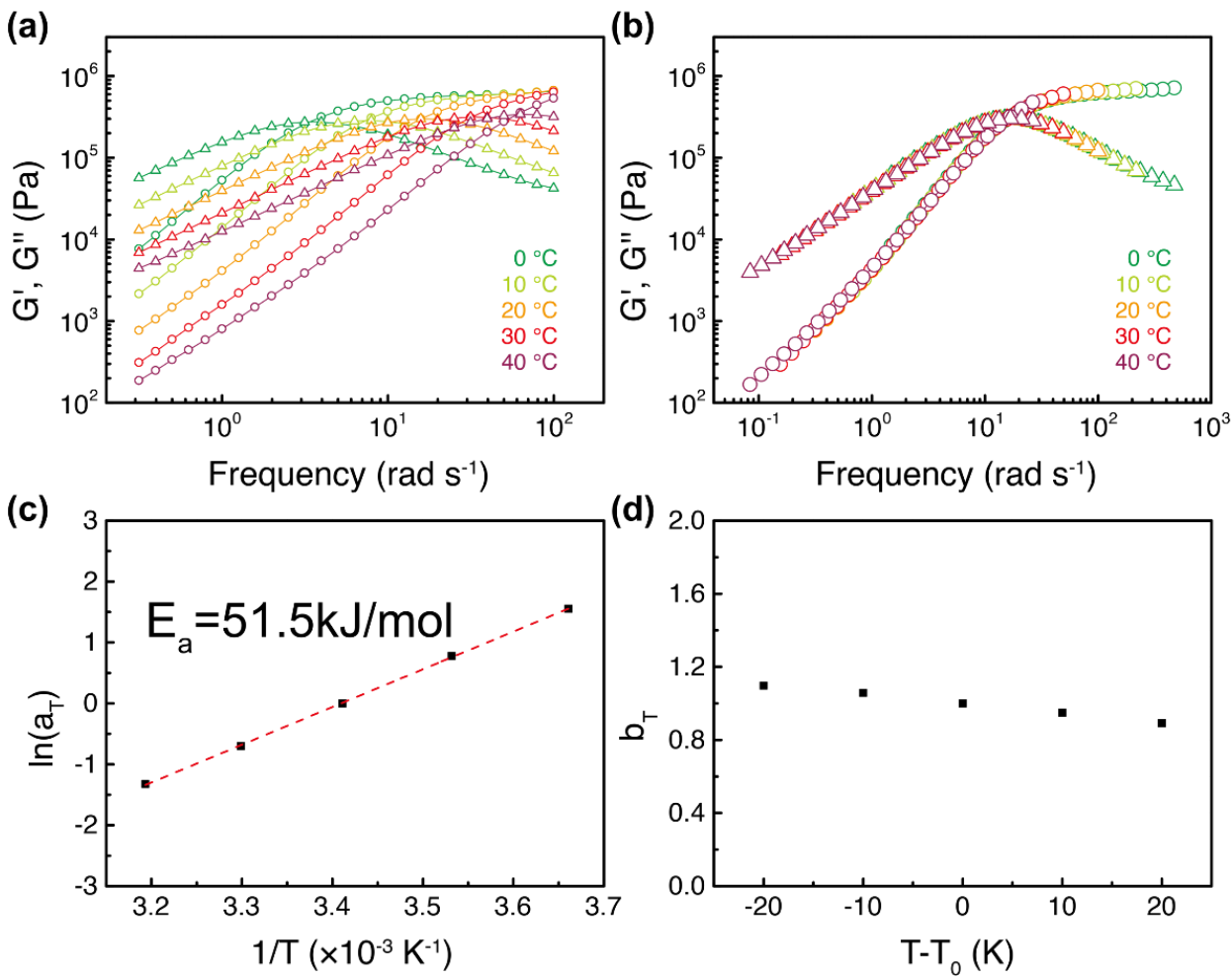

Figure S14. Dynamic mechanical behavior of Tb-L $\mathrm{L}_{2} \mathrm{EO}_{4}-\mathrm{PMPTC}$ hydrogels with $0.3 \mathrm{M}$ NaCl. (a) Temperature effect on the rheological behavior. (b) Classical time-temperature superposition shifts at a reference temperature of $20^{\circ} \mathrm{C}$. (c) Time-temperature horizontal shift factor $\left(\mathrm{a}_{\mathrm{T}}\right)$ derived from Arrhenius equation. The apparent activation energy of $51.5 \mathrm{~kJ} \mathrm{~mol}^{-1}$ were calculated from the slope of the curve. (d) Vertical shift factor $\left(\mathrm{b}_{\mathrm{T}}\right)$ as a function of temperature.

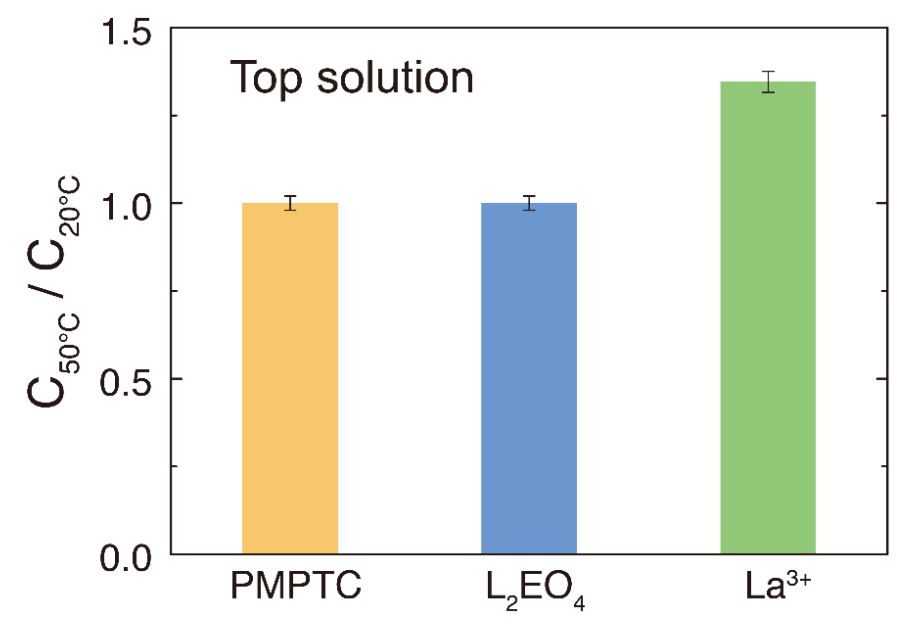

Figure S15. The concentrations (normalized by the original value $\mathrm{C}_{15}{ }^{\circ} \mathrm{C}$ ) for three components in top solution at $50{ }^{\circ} \mathrm{C}$. The (low) concentrations of PMPTC and $\mathrm{L}_{2} \mathrm{EO}_{4}$ in the supernatant solution remain constant upon heating, while the concentration of $\mathrm{La}^{3+}$ increases by about $30 \%$. As most lanthanide ions ( $\sim 87 \%)$ are in the hydrogel phase, the $30 \%$ change of lanthanide ions in the top phase implies only a minor (4\%) decrease of lanthanide ion concentration in the gel. 


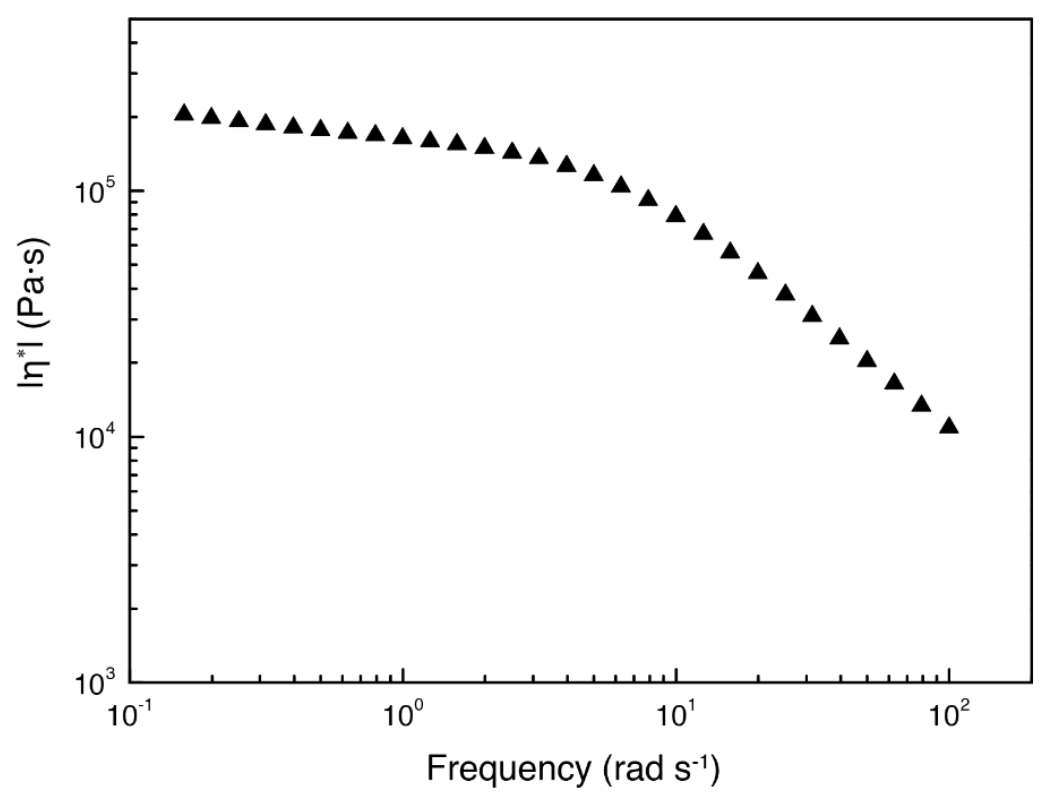

Figure S16. Frequency dependency of the complex viscosity $(|\eta *|)$ of $\mathrm{Tb}-\mathrm{L}_{2} \mathrm{EO}_{4}-\mathrm{PMPTC}$ hydrogel at $20{ }^{\circ} \mathrm{C}$ with $50 \mathrm{mM} \mathrm{NaCl}$.

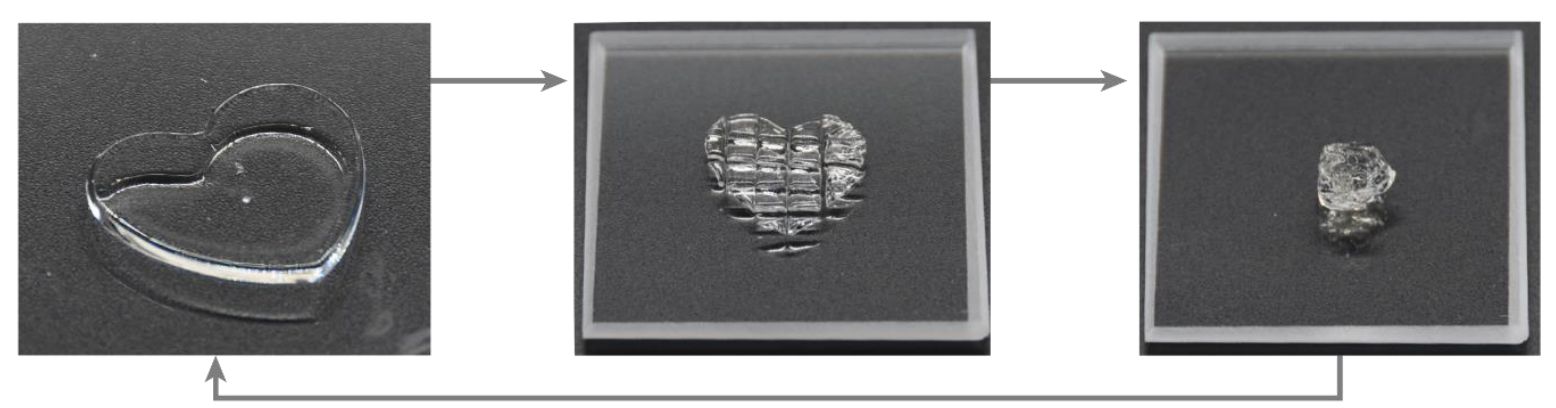

Figure S17. The $\mathrm{Tb}-\mathrm{L}_{2} \mathrm{EO}_{4}-\mathrm{PMPTC}$ hydrogel is recyclable. Even if the hydrogel dehydrates, it can recover $>95 \% \mathrm{G}^{\prime}$ in several dehydration-hydration cycles. 
(a)

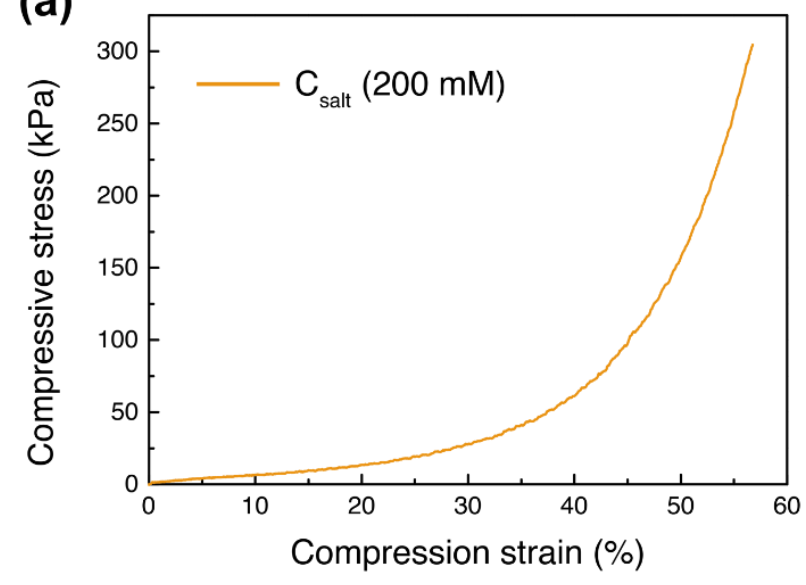

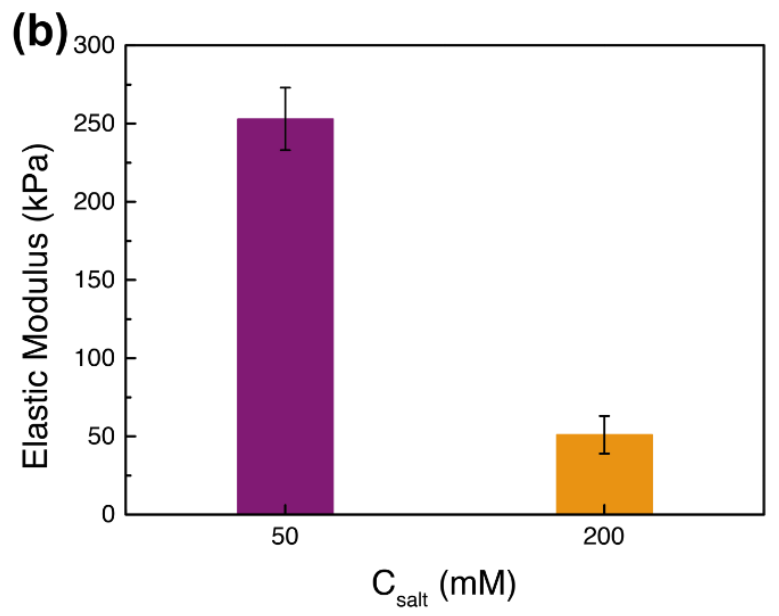

Figure S18. (a) A typical compression stress-strain curve of the $\mathrm{Tb}-\mathrm{L}_{2} \mathrm{EO}_{4}-\mathrm{PMPTC}$ hydrogel with salt concentration of $200 \mathrm{mM} \mathrm{NaCl}$. (b) The elastic modulus of the hydrogels at different salt concentrations.

(a)

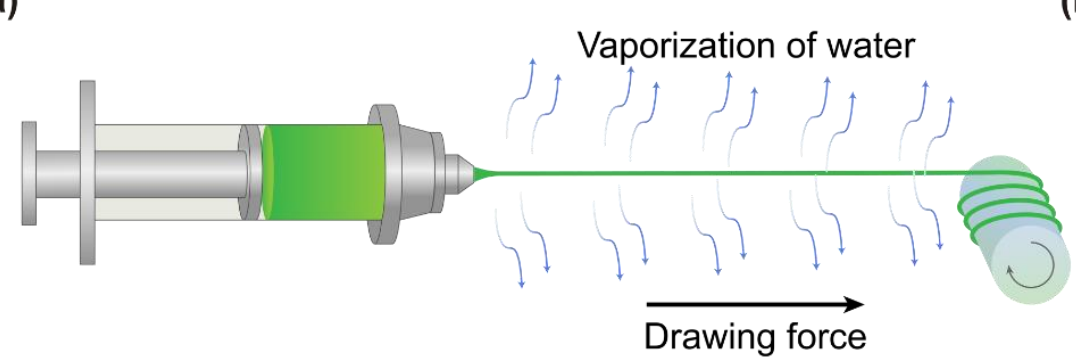

(b)

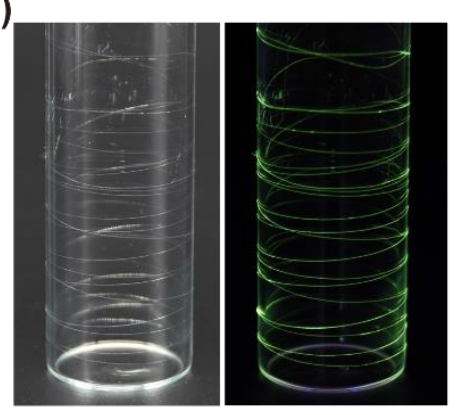

Figure S19. (a) Schematic draw-spinning method to generate luminescent microfibers.

(b) Fiber drawn from Tb- $\mathrm{L}_{2} \mathrm{EO}_{4}-\mathrm{PMPTC}$ hydrogel reservoir $(200 \mathrm{mM} \mathrm{NaCl})$.

(a)
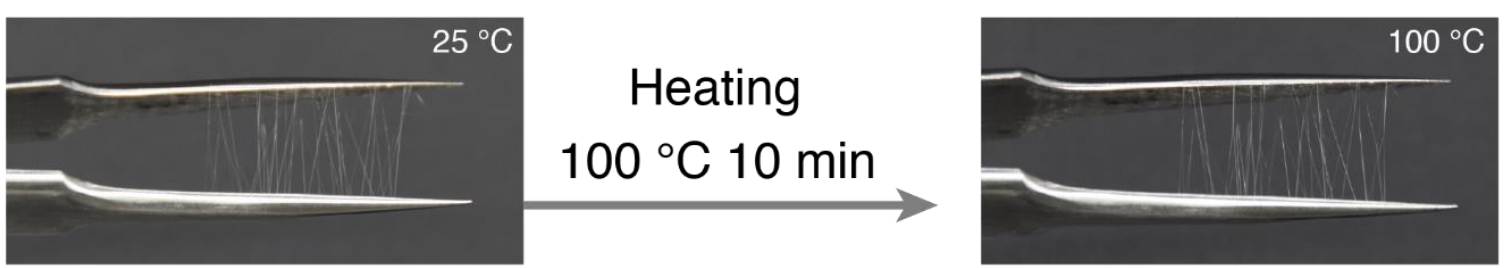

(b)
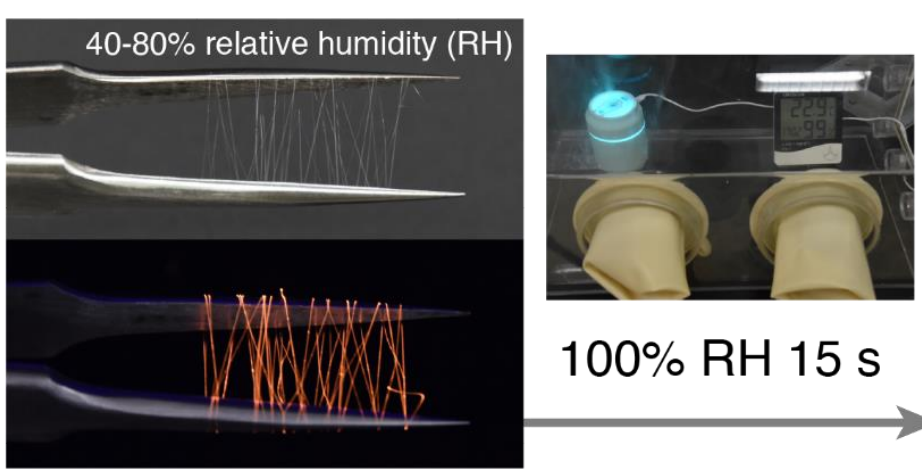

$100 \% \mathrm{RH} 15 \mathrm{~s}$

Figure S20. (a) Thermal stability of the fiber. (b) Performance of the fiber humidity sensor. 
Table S1. The apparent activation energy $\left(E_{\mathrm{a}}\right)$ of $\mathrm{Tb}-\mathrm{L}_{2} \mathrm{EO}_{4}-\mathrm{PMPTC}$ hydrogels with various salt concentrations.

\begin{tabular}{lrrrrrrr}
\hline $\mathrm{C}_{\text {salt }}(\mathrm{mM})$ & 50 & 147 & 240 & 330 & 416 & 500 & 580 \\
$E_{\mathrm{a}}\left(\mathrm{kJ} \mathrm{mol}^{-1}\right)$ & 55 & 54.6 & 54.4 & 51.5 & 52.4 & 50.4 & 51.3 \\
\hline
\end{tabular}

\section{References}

(1) Li, C.; Rowland, M. J.; Shao, Y.; Cao, T.; Chen, C.; Jia, H.; Zhou, X.; Yang, Z.; Scherman, O. A.; Liu, D. Responsive Double Network Hydrogels of Interpenetrating DNA and CB[8] Host-Guest Supramolecular Systems. Adv. Mater. 2015, 27, 3298-3304.

(2) Wu, Y. C.; Shah, D. U.; Liu, C. Y.; Yu, Z. Y.; Liu, J.; Ren, X. H.; Rowland, M. J.; Abell, C.; Ramage, M. H.; Scherman, O. A. Bioinspired supramolecular fibers drawn from a multiphase self-assembled hydrogel. Proc. Natl. Acad. Sci. U.S.A. 2017, 114, 8163-8168.

(3) Lemmers, M.; Sprakel, J.; Voets, I. K.; van der Gucht, J.; Stuart, M. A. C. Multiresponsive Reversible Gels Based on Charge-Driven Assembly. Angew. Chem. Int. Ed. 2010, 49, 708-711. (4) Srivastava, S.; Andreev, M.; Levi, A. E.; Goldfeld, D. J.; Mao, J.; Heller, W. T.; Prabhu, V. M.; de Pablo, J. J.; Tirrell, M. V. Gel phase formation in dilute triblock copolyelectrolyte complexes. Nat. Commun. 2017, 8, 14131.

(5) Sun, Y. T.; Wollenberg, A. L.; O'Shea, T. M.; Cui, Y. X.; Zhou, Z. H.; Sofroniew, M. V.; Deming, T. J. Conformation-Directed Formation of Self-Healing Diblock Copolypeptide Hydrogels via Polyion Complexation. J. Am. Chem. Soc. 2017, 139, 15114-15121.

(6) Martinez-Calvo, M.; Kotova, O.; Mobius, M. E.; Bell, A. P.; McCabe, T.; Boland, J. J.; Gunnlaugsson, T. Healable luminescent self-assembly supramolecular metallogels possessing lanthanide $(\mathrm{Eu} / \mathrm{Tb})$ dependent rheological and morphological properties. J. Am. Chem. Soc. 2015, 137, 1983-1992.

(7) Grindy, S. C.; Learsch, R.; Mozhdehi, D.; Cheng, J.; Barrett, D. G.; Guan, Z. B.; Messersmith, P. B.; Holten-Andersen, N. Control of hierarchical polymer mechanics with bioinspired metal-coordination dynamics. Nat. Mater. 2015, 14, 1210-1216.

(8) Holten-Andersen, N.; Harrington, M. J.; Birkedal, H.; Lee, B. P.; Messersmith, P. B.; Lee, K. Y. C.; Waite, J. H. pH-induced metal-ligand cross-links inspired by mussel yield self-healing polymer networks with near-covalent elastic moduli. Proc. Natl. Acad. Sci. U.S.A. 2011, 108, 
2651-2655.

(9) Weng, G. S.; Thanneeru, S.; He, J. Dynamic Coordination of Eu-Iminodiacetate to Control Fluorochromic Response of Polymer Hydrogels to Multistimuli. Adv. Mater. 2018, 30, 1706526. (10) Sun, Z.; Lv, F.; Cao, L.; Liu, L.; Zhang, Y.; Lu, Z. Multistimuli-Responsive, Moldable Supramolecular Hydrogels Cross-Linked by Ultrafast Complexation of Metal Ions and Biopolymers. Angew. Chem. Int. Ed. 2015, 54, 7944-7948.

(11) Li, Z. Q.; Wang, G. N.; Wang, Y. G.; Li, H. R. Reversible Phase Transition of Robust Luminescent Hybrid Hydrogels. Angew. Chem. Int. Ed. 2018, 57, 2194-2198.

(12) Tamesue, S.; Ohtani, M.; Yamada, K.; Ishida, Y.; Spruell, J. M.; Lynd, N. A.; Hawker, C. J.; Aida, T. Linear versus dendritic molecular binders for hydrogel network formation with clay nanosheets: studies with ABA triblock copolyethers carrying guanidinium ion pendants. $J$. Am. Chem. Soc. 2013, 135, 15650-15655.

(13) Sun, S.; Mao, L. B.; Lei, Z.; Yu, S. H.; Cölfen, H. Hydrogels from Amorphous Calcium Carbonate and Polyacrylic Acid: Bio-Inspired Materials for "Mineral Plastics". Angew. Chem. Int. Ed. 2016, 55, 11765-11769. 